\title{
Sobretratamento restaurador: relato de caso e discussão sobre a decisão do tratamento restaurador
}

\author{
Luiz Alexandre CHISINI'; Marcella Satte Alam GONÇALVES²; Luana Carla \\ SALVI ${ }^{3}$; Francine dos Santos COSTA ${ }^{4}$; Marcus Cristian Muniz CONDE ${ }^{5}$
}

\begin{abstract}
1 - Doutor em odontologia, Professor de odontologia, Universidade do Vale do Taquari, Centro de Ciências Biológicas e da Saúde, Lajeado, Rio Grande do Sul, Brasil; 2 - Acadêmica de Odontologia, Universidade Federal de Pelotas, Pelotas, Rio Grande do Sul, Brasil; 3 - Bióloga, Mestranda em Ambiente e Desenvolvimento, Universidade do Vale do Taquari, Centro de Ciências Biológicas e da Saúde, Lajeado, Rio Grande do Sul, Brasil; 4 - Doutora em odontologia e Epidemiologia, Professora de odontologia, Universidade do Vale do Taquari, Centro de Ciências Biológicas e da Saúde, Lajeado, Rio Grande do Sul, Brasil; 5 - Doutor em odontologia, Professor de odontologia, Universidade do Vale do Taquari, Centro de Ciências Biológicas e da Saúde, Lajeado, Rio Grande do Sul, Brasil.
\end{abstract}

\section{Resumo}

O objetivo do presente estudo foi relatar um caso clínico de sobretratamento restaurador e discutir os aspectos relacionados ao diagnóstico e a conduta clínica frente a lesões de cárie. A paciente do sexo feminino $(22$ anos) procurou atendimento odontológico na Faculdade de Odontologia da Universidade Federal de Pelotas. Durante o acolhimento a paciente relatou ter sido diagnosticada com diversas lesões de cárie e com a necessidade de tratamento restaurador. Os exames periodontais supragengivais demonstraram um índice de Placa Visível de 8,3\% e um índice de sangramento gengival de $13,54 \%$. Nenhuma profundidade de sondagem maior que $3 \mathrm{~mm}$ foi observada. Ao Exame de ICDAS (International Caries Detection and Assessment System) foram observadas diversas lesões inativas de cárie, cavitadas e não cavitadas, scores ICDAS 2 e 3 . Foram observadas restaurações de resina composta (classe I) nas superfícies oclusais dos elementos 16, 26 e 46. Desta forma, a paciente foi diagnosticada com ausência da doença cárie e com gengivite leve induzida por biofilme. Orientações de higiene bucal foram discutidas para o tratamento da gengivite e o acompanhamento das lesões de cárie foram indicados para o caso. Após 1 ano de acompanhamento, as lesões inativas não se alteraram, demonstrando que abordagens conservadoras são uma ótima opção, além de evitarem o sobretratamento restaurador. O presente estudo utiliza como background o presente relato de experiência para discutir o manejo da cárie dental e a indicação do tratamento restaurador baseado em evidências científicas.

PALAVRAS-CHAVE: Cárie dentária; Tomada de decisões; Relato de caso.

Copyright @ 2021 Revista Odontológica do Brasil Centra Esta obra está licenciada com uma licença Atribuição-NãoComerciaCompartilhalgual 4.0 Internaciona (CC BY-NC-SA 4.0)

Recebido: 29/04/21 Aceito: $21 / 06 / 21$ Publicado: 23/07/21

\section{AUTOR PARA CORRESPONDÊNCIA}

Prof. Dr. Luiz Alexandre Chisini

Rua Avelino Talini, n.171 - Lajeado, Rio Grande do Sul, Brasil, CEP: 95914-014

Tel: +55 53 98112-1141

E-mail: alexandrechisini@gmail.com 


\section{Introdução}

A cárie dental é uma doença multifatorial fortemente influenciada pelas condições socioeconômicas e pela composição da $\operatorname{dieta}^{1-3}$, podendo culminar na perda do elemento dental ${ }^{4,5}$. Além disso, estudos têm apresentado um importante componente genético capaz de influenciar sua prevalência ${ }^{6-8}$. A cárie dental é uma doença biofilme-açúcar dependente sendo causada por um desequilíbrio entre os minerais dos tecidos dentais e o fluído do biofilme ${ }^{9}$, assim, o esmalte e dentina perdem ou ganham minerais de acordo com as condições de saturação dos fluídos do meio bucal $^{10}$. Neste contexto, o pH dos fluídos é o fator determinante para o processo des/remineralização, uma vez que a solubilidade do mineral dental está ligada ao $\mathrm{pH}^{11}$. Assim, a cárie dental é frequentemente causada por uma alteração na dieta ou uma redução do fluxo salivar. Ambas associadas a um inadequado controle do biofilme dental ${ }^{12,13}$. Neste contexto, ela está diretamente relacionada com fatores comportamentais, sociais e econômicos, sendo considerada como a doença de maior prevalência da cavidade oral ${ }^{14}$. No entanto, a doença pode ser interrompida se eliminados os principais fatores etiológicos; desta forma, conduzindo o paciente a um estado de saúde. Para que isso ocorra, o controle do biofilme dental e o controle da dieta (redução de carboidratos fermentáveis) devem ser realizados ${ }^{1,8}$. Além disso, é importante que ocorra a disponibilidade de fluoretos pela água de abastecimento público ou por meio de dentifrício ${ }^{10,12,13,15}$. Assim, o cirurgião-dentista deve conhecer e saber identificar os componentes da atividade da doença para poder tomar a melhor decisão de tratamento que, em casos de lesões restritas à esmalte - independente da atividade da lesão - não é restauradora.

A formulação do plano de tratamento é um dos pontos mais importantes da rotina do cirurgião-dentista e a decisão de intervenção restauradora deve ser realizada com embasamento científico. No entanto, o estabelecimento de um correto diagnóstico necessita de muito conhecimento em relação aos determinantes da doença cárie, suas manifestações nos tecidos dentais e sua 
histopatologia ${ }^{10,12,13}$. A utilização de exames complementares ${ }^{16}$, tais como as radiografias, se faz muitas vezes necessária para determinar a extensão de cavidades em lesões não cavitadas de cárie que envolvam a dentina, as quais se tornam, muitas vezes, difíceis de serem mensuradas apenas nos exames clínicos ${ }^{17}$.

Vários estudos têm evidenciado diferentes abordagens clínicas entre os cirurgiões-dentistas de diferentes países ${ }^{18-22}$, observando, em sua maioria, um perfil intervencionista, os quais tendem a intervir em lesões iniciais de cárie e em restaurações com pigmentação marginal sem que exista - de fato - a necessidade para $\mathrm{tal}^{20-22}$. Desta forma, o presente estudo tem como objetivo apresentar um caso clínico de sobretratamento restaurador e discutir aspectos relacionados com o diagnóstico e a conduta clínica frente a lesões de cárie dental.

\section{Relato de caso}

A paciente do sexo feminino (22 anos) buscou atendimento odontológico na Faculdade de Odontologia da Universidade Federal de Pelotas. Durante o atendimento a paciente relatou ter sido diagnosticada com diversas lesões de cárie e com a necessidade de tratamento restaurador. Reportou estar preocupada, pois havia sido informada por um dentista que as lesões de cárie iriam progredir se não fossem restauradas, podendo necessitar futuramente de tratamento endodôntico. Informou, também, que realizou algumas restaurações com esse profissional e procurou atendimento da faculdade, pois estava com dificuldades financeiras para realizar todo o tratamento proposto pelo profissional.

Após avaliação clínica e radiográfica (Figuras 1-3), foram observados os seguintes achados: exames periodontais supragengivais: Índice de Placa Visível (IPV): 8,3\%; Índice de Sangramento Gengival (ISG): 13,54\%; Fator Retentivo de Placa (FRP): 16,66\%, exames periodontais subgengivais: Profundidade de Sondagem (PS): não apresentou profundidade de sondagem maior que $3 \mathrm{~mm}$; Sangramento à Sondagem (SS): presente em 23 dentes; 
Nível de inserção (NI) e Furca todos condizentes com saúde. Paciente apresenta fluorose muito leve, segundo índice de Dean. Exame de ICDAS (International Caries Detection and Assessment System): presença de lesões de cárie inativas com opacidade visível na presença de umidade (escore 2-) nos elementos 15, 17, $25,27,33,34,36,43,44,45$ e 47 , e cavidades em esmalte inativas (escores 3-) nos elementos 25, 26, 36 e 46. Foram observadas restaurações em resina composta nas superfícies oclusais dos elementos 16, 26 e 46.

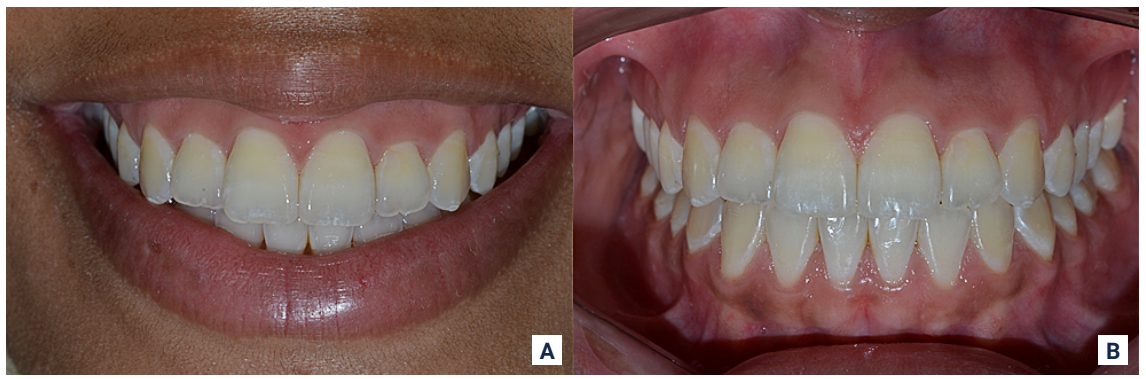

FIGURA 1 - Imagem intraoral da paciente. (A) Sorriso; (B) observamos manchas brancas de cerca de $1 \mathrm{~mm}$ nas pontas das cúspides, indicando fluorose no estágio leve pelo índice de Dean)

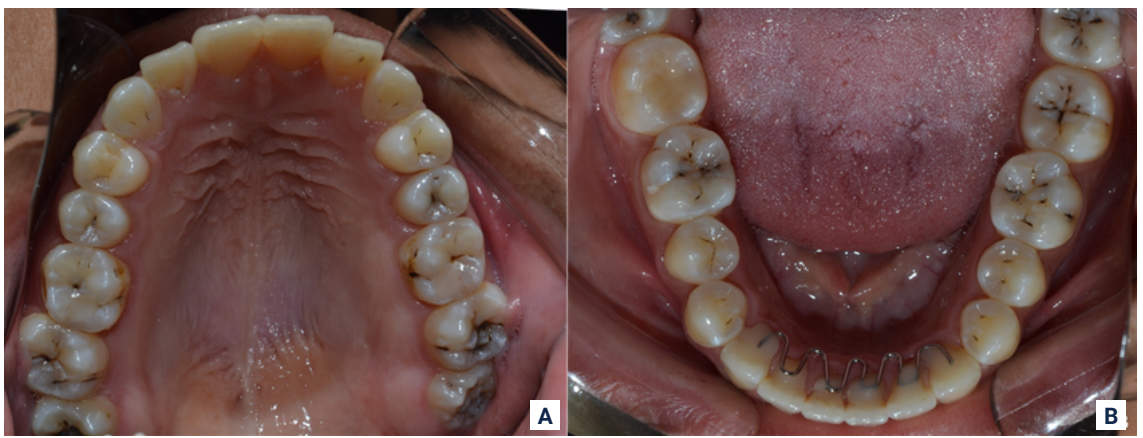

FIGURA 2 - Imagem intraoral do arco superior e inferior. (A) Podemos observar diversas lesões inativas de cárie nas superfícies oclusais de molares e pré-molares. Elementos 16 e 26 apresentam restaurações de resina composta nas superfícies oclusais; (B) lesões inativas nas superfícies oclusais de molares e pré-molares e restauração em resina composta no elemento 46.

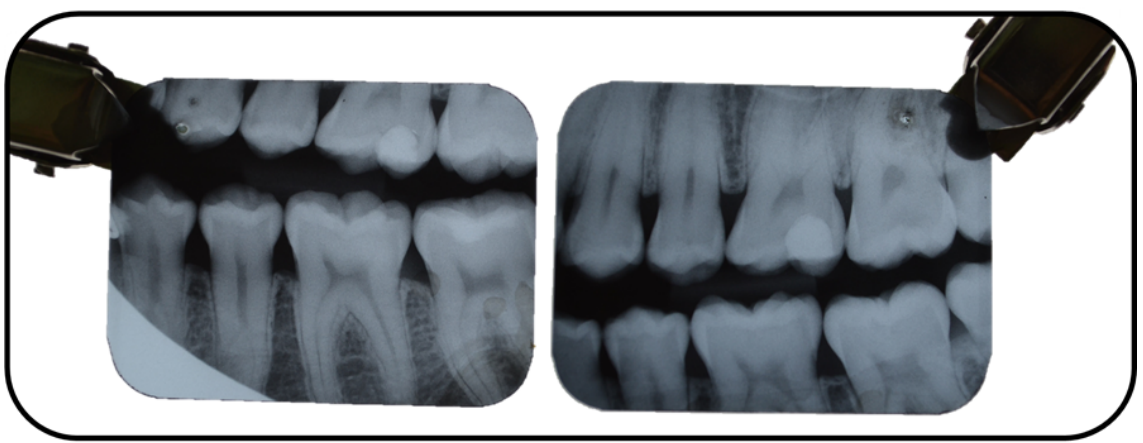

FIGURA 3 - Exames radiográficos interproximais na região de molares e pré-molares. As lesões de cárie são restritas ao terço externo de dentina (elementos $27,37,36,46,47$ ) 
Ao final dos exames, a paciente foi diagnosticada com ausência da doença cárie e com gengivite leve induzida por biofilme. Desta forma, foi realizada a instrução de higiene bucal para reverter os sítios (disto-linguais, linguais e mésio-linguais dos elementos 33, 32, 31, 41, 42, 43, 16; mésio lingual e disto lingual do 17) que apresentavam gengivite. Além disso, foi explicado à paciente que ela apresentava boa saúde bucal e a realização de tratamento restaurador seria contraindicada. Após esclarecimento das dúvidas da paciente, a mesma foi instruída e alertada dos riscos de sobretratamento odontológico e que lesões inativas de cárie apresentam um baixo risco de reativarem e progredirem ${ }^{23}$. A paciente foi orientada a comparecer apenas às consultas periódicas para o acompanhamento das lesões inativas e do controle da gengivite localizada. Após 1 ano de acompanhamento, as lesões inativas não se alteraram, demonstrando que abordagens conservadoras são uma ótima opção, além de evitarem o sobretratamento restaurador.

\section{Discussão}

Diversos estudos têm demonstrado que existe uma grande variabilidade clínica entre os cirurgiões-dentistas em relação à decisão do tratamento restaurador ${ }^{19-22}$. De forma semelhante ao observado no presente caso, a literatura reporta uma grande tendência intervencionista de dentistas ${ }^{20-22}$, mesmo em situações clínicas onde existe forte evidência científica para tratamentos não operatórios. No presente caso, observamos uma tendência do cirurgião-dentista em abordar a lesão inativa (sulco pigmentado) da paciente, enquanto a literatura científica claramente preconiza a não intervenção de lesões restritas ao esmalte. Além disso, a literatura, até pouco tempo, carecia de consenso em relação ao momento específico em que uma lesão necessita de intervenção restauradora, muitas vezes sendo contraditória em relação à referência/bibliografia utilizada ${ }^{23}$. Desta forma, recentes publicações têm apresentado, por meio de um Expert Delphi Consensus Statement, recomendações no manejo de lesões de 
cárie ${ }^{23,24}$. Talvez este seja um dos fatos que ajude a explicar essa grande diferença de conduta clínica observada entre os profissionais ${ }^{19-21}$. No entanto, existe uma consonância na literatura científica mundial no que tange as lesões restritas ao esmalte dental. Havendo assim, uma contraindicação do tratamento restaurador operatório neste tipo de lesão, sendo a lesão ativa ou inativa, cavitada ou não ${ }^{10,25-28}$. Isto se deve ao grande potencial de remineralização deste tipo de lesão, que é passível de reversão do quadro clínico uma vez que o paciente retorne para um quadro de saúde $27,29,30$.

A dificuldade em determinar o diagnóstico da cárie está no processo dinâmico de desmineralização e remineralização que ela apresenta $^{30}$. Embora diversos métodos na detecção das lesões tenham sido desenvolvidos ${ }^{31-33}$, o padrão-ouro ainda é o método tátil-visual ${ }^{32}$, realizado preferencialmente com a utilização da sonda OMS, que evita a fratura do esmalte dental. Ainda, em determinadas circunstâncias, pode ser auxiliado por exames radiográficos complementares pela técnica interproximal ${ }^{17}$, como realizado no caso clínico, objetivando investigar a extensão das restaurações. Desta forma, é importante determinar a atividade/ inatividade da lesão $0^{28,34}$. Lesões ativas em esmalte são caracterizadas por apresentarem uma coloração branca, sem brilho, opaca e rugosa (aspecto de giz), enquanto que a lesão inativa em esmalte é caracterizada por uma mancha mais escurecida (marrom/ preta) que pode apresentar-se mais ou menos pigmentada, com superfície de esmalte lisa e brilhosa ${ }^{28,34}$. Em dentina, lesões ativas apresentam uma coloração amarelada, acastanhada ou marrom clara, geralmente coberta por biofilme com consistência de couro à sondagem com pressão moderada ${ }^{28,34}$. Já as lesões inativas em dentina apresentam-se com aspecto brilhante, relativamente uniforme, resistente à sondagem, com coloração que pode variar do marrom ao preto, geralmente sem depósito microbiano ${ }^{28,34}$.

De fato, qualquer lesão passível de higienização (cavitada ou não) pode ser inativada apenas com a mudança dos hábitos dos pacientes, 
controlando o biofilme bacteriano e a dieta cariogênica ${ }^{25,30}$. Neste contexto, a utilização de agentes fluoretados são de extrema importância, pois diminuem a perda mineral dos tecidos dentais através da formação de fluoreto de cálcio, que atua como um reservatório de fluoretos, e do mecanismo de remineralização ${ }^{10,29,30}$, enquanto as intervenções são direcionadas ao comportamento do paciente, objetivando o retorno ao estado de saúde bucal ${ }^{25}$.

Quando o profissional encontra uma maior dificuldade para conduzir o paciente para um estado de saúde bucal - através da mudança de comportamento - e os riscos das lesões iniciais de cárie (escores 1 a 4 ativos do ICDAS) transformarem-se em cavidades em dentina (escores 5 e 6 do ICDAS) sejam elevadas, a utilização de tratamentos minimamente invasivos pode ser uma estratégia interessante $^{28,35}$ (Quadro 1). Dentre essas abordagens, estão incluídos os selamentos de sulcos e cavidades e as resinas infiltrativas $^{24}$. No entanto, neste ponto é importante ressaltar que os riscos individuais dos pacientes devem ser investigados com cautela para classificá-los como indivíduos de al to risco de progressão da doença ${ }^{36}$. No presente caso, a paciente foi classificada com baixo risco de cárie dental, uma vez que a frequência e o consumo de sacarose eram baixos, estava exposta à fluoretos (água de abastecimento público e dentifrícios) e apresentava um baixo IPV.

\begin{tabular}{|c|c|c|}
\hline Alvo & Intervenção & Invasividade \\
\hline Biofilme & $\begin{array}{l}\text { Mecânico: Higiene oral (instrução, escovaçõ } \\
\text { profissional) } \\
\text { Químico: Antimicrobiano }\end{array}$ & \\
\hline Dieta & $\begin{array}{l}\text { Modificação da dieta (aconselhamento) } \\
\text { Substituição do açúcar }\end{array}$ & Não invasivo \\
\hline Mineralização & $\begin{array}{l}\text { Substâncias que promovem a mineralização: flúor e } \\
\text { componentes com cálcio } \\
\text { Estimular o fluxo salivar / substitutos da saliva }\end{array}$ & \\
\hline Difusão & $\begin{array}{l}\text { Selantes } \\
\text { Infiltração }\end{array}$ & Micro invasivo \\
\hline Sinais/sintomas & Restauração & Minimamente in \\
\hline
\end{tabular}

QUADRO 1 - Tipos de tratamentos para à cárie dental de acordo com a invasividade 
Os selantes, que podem ser compostos por diferentes materiais (resinas compostas, cimentos de ionômero de vidro e ionômero de vidro modificado por resina, por exemplo) fazem um barreira mecânica na superfície dental, com isso as lesões de cárie tendem a se inativar ${ }^{35}$. No entanto, assim como todo o material restaurador, os selantes devem ser acompanhados, pois em algum momento podem vir a falhar e se tornarem fatores retentivos de biofilme ${ }^{35}$. Estima-se que a taxa de retenção de selantes, após um ano, seja de $90 \%$ e, após 15 anos, de apenas $28 \%{ }^{37}$. Além disso, selantes resinosos parecem ter uma maior retenção, o que não descarta o seu acompanhamento periódico ${ }^{38}$. A resina infiltrativa, por sua vez, é uma técnica onde se condiciona a estrutura dental com um ácido (frequentemente o clorídrico) objetivando ampliar a permeabilidade do material no local da cárie dental ${ }^{39}$. Posteriormente, com uma resina de baixa viscosidade, é realizada a penetração do material resinoso nos poros do corpo da lesão. Dessa forma, a resina infiltrada é fotoativada ${ }^{40}$. Devido a essa técnica ser recente, estudos avaliando sua efetividade à longo prazo não são ainda disponíveis na literatura. Assim, tanto o infiltrante resinoso como o selante evitam a penetração de ácidos e substratos para microrganismos na região, impedindo a progressão da lesão ${ }^{40}$. No entanto, eles devem ser indicados apenas para usuários que não responderam aos tratamentos não invasivos (controle de higiene bucal, aplicação tópica de flúor e controle de dieta) e o risco de cavitação em dentina das lesões seja elevada ${ }^{25,36}$.

Em lesões de escore 4 do exame ICDAS (lesões fechadas com sombreamento em dentina) a divergência de conduta clínica tanto entre os profissionais quanto na literatura é grande ${ }^{22}$. Tendo em vista as filosofias mais conservadoras no manejo da cárie dental, a Figura 4 resume a indicação do tratamento restaurador baseado na mínima intervenção restauradora ${ }^{28,41}$. Assim, é importante observar que lesões escore 4 do ICDAS irão progredir sempre que existir cavidade abaixo da lesão sombreada, mesmo que a doença esteja controlada ${ }^{42}$. Em contrapartida, 
lesões sombreadas em dentina sem cavidade não irão progredir se a doença estiver sob controle ${ }^{25,26,31}$. Desta forma, a presença de cavidade é um critério importante para a necessidade de tratamento restaurador e o exame radiográfico é de fundamental importância para avaliarmos a extensão destas lesões ${ }^{42}$. Assim, estima-se que uma pequena parcela (cerca de 10\%) das lesões que estejam radiograficamente restritas à esmalte apresentem cavidades próximo à junção amelo-dentinária ${ }^{28,43,44}$.

\begin{tabular}{|c|c|c|c|c|c|}
\hline \multirow[t]{2}{*}{ Diagnóstico } & \multirow{2}{*}{$\begin{array}{c}\text { Carie Inativa } \\
\text { (Sem progressäo) }\end{array}$} & \multicolumn{4}{|c|}{ Paciente Com Atividade da Doença (Cárie Ativo) } \\
\hline & & Iniciais & Iniciais & Médias & Profunda \\
\hline Exame Tátil-Visual & $\begin{array}{l}\text { Todos scores do ILDAS } \\
\text { (Lesōes inativas) }\end{array}$ & ICDASI. 2 e 3 & ICDAS 3 e 4 & ICDAS 4 & ICDAS 5 e 6 \\
\hline Exame Radiográfico & - & - & $1 / 3$ externo dentina & 2/3 médio dentina & - \\
\hline & & Esmalte & Esmalte/Dentina & Dentina & Dentina \\
\hline Terapia & Nenhuma & \begin{tabular}{|c|} 
Preventiva \\
(controle da doença)
\end{tabular} & \begin{tabular}{c|} 
Preventiva \\
(controle da doença)
\end{tabular} & Restaurador & $\begin{array}{c}\text { Restaurador } \\
\text { (Proteçẵo pulpar) }\end{array}$ \\
\hline
\end{tabular}

FIGURA 4 - Quadro esquemático para a decisão do tratamento restaurador baseado na filosofia de mínima intervenção restauradora ${ }^{42}$

Quando a imagem radiográfica se estende para o terço externo de dentina, estima-se que uma pequena parcela das lesões (cerca de $32 \%$ ) estejam cavitadas, não justificando ainda o tratamento restaurador ${ }^{28,43,44}$. Desta forma, estas lesões (escore 4 do ICDAS com imagem radiolúcida próxima à junção amelodentinária) devem ser acompanhadas radiograficamente, para determinar se uma lesão progrediu ou não, são necessárias duas radiografias com um espaço de tempo entre elas ${ }^{28,43,44}$. No entanto, quando a imagem radiográfica se estende para terço médio de dentina, estima-se que uma grande parcela dessas lesões (72\%) já estejam cavitadas, necessitando assim de tratamento restaurador ${ }^{28,41,43,44}$.

Desta forma, a evidência atual indica que a profundidade de penetração radiográfica, na qual se pode prever de forma segura que a superfície do dente é cavitada e a dentina fortemente infectada, está na região de maior radiolucidez que o terço 
externo de dentina, ou seja, terço médio ou terço interno de dentina ${ }^{28,41,43,44}$. Nas demais lesões (ICDAS escore 5 e 6) o tratamento restaurador se justifica pelo fato de restabelecimento da função biológica, comprometida pela perda de estrutura ${ }^{28,41,43,44}$. No entanto, desde que tais lesões possam ser higienizadas, elas apresentam potencial de inativação $0^{29}$.

Ainda, é importante enfatizar a importância da padronização do diagnóstico das lesões de cárie entre os profissionais utilizando os mesmos critérios ${ }^{45}$. Isso auxilia a comunicação entre os profissionais, a comparação entre diferentes estudos e a formulação do plano de tratamento ${ }^{46}$. Embora o índice CPO-D/ CPO-S (dentes/superfícies cariadas, perdidas e obturadas) seja o mais utilizado em estudos epidemiológicos, ele não detecta lesões incipientes de cárie ${ }^{46}$. Assim, a contribuição do Sistema Internacional de Detecção e Avaliação de Cárie (ICDAS) para o diagnóstico de cárie dentária é inquestionável e por isso ele tem sido o índice recomendado para a utilização clínica dos profissionais. Ele detecta lesões de cárie desde a sua primeira alteração visível no esmalte (onde o tratamento é não operatório) até cavitações extensas dentro da dentina visível ${ }^{46}$. Mesmo quando usado por examinadores inexperientes, o ICDAS expande o espectro de diagnóstico de cárie dentária em ambientes clínicos, de pesquisa, ensino e epidemiologia.

Devido a todos estas nuances, muitas vezes de difícil padronização, os clínicos apresentam dificuldade em realizar um correto diagnóstico clínico de lesões de cárie dental e consequente indicação de tratamento restaurador, reforçando a necessidade de maiores discussões a respeito do tópico ${ }^{19-22,17}$, principalmente com a finalidade de diminuir o sobretratamento destas lesões. Neste sentido, uma análise geoespacial observou que cirurgiões-dentistas que atuam em regiões com maior número de profissionais tendem a apresentar posturas mais intervencionistas do que profissionais que atuam em ambientes menos competitivos ${ }^{47}$. Talvez este fator possa justificar (ao menos em parte) a frequente 
indicação de sobretratamento por dentistas Brasileiros ${ }^{48}$, uma vez que o mercado de trabalho odontológico se encontra saturado e altamente competitivo, com um número muito maior de profissionais por habitante que o recomendado pela Organização Mundial da Saúde ${ }^{48}$.

Desta forma, profissionais podem estar indicando tratamentos desnecessários por motivação econômica. O sobretratamento de lesões iniciais de cárie afeta significativamente a longevidade do elemento dental, além de remover grande quantidade de estrutura dental sadia, conduzindo o elemento dental pra o chamado ciclo restaurador repetitivo ${ }^{49}$. Ademais, uma vez que se iniciar o tratamento restaurador o mesmo estará sujeito a falhas com o decorrer dos anos assim como estará sujeito ao desgaste do material, que necessitará de acompanhamento. Além disso, restaurações em resina composta classe I e II em dentes permanentes apresentam uma taxa de falha anual de 1 a $3 \%{ }^{50}$ e de 1,7 a $12,9 \%$ em dentes decíduos ${ }^{51}$, o que significa que com o transcorrer dos anos estas restaurações poderão vir a falhar. Neste contexto, uma vez que evitamos o início do tratamento operatório e o início do ciclo restaurador repetitivo, aumentamos a longevidade do elemento dental.

\section{Conclusões}

A literatura demonstra que o sobretratamento restaurador é frequente entre dentistas de diversos países, incluindo o Brasil. No entanto, as novas filosofias de odontologia minimamente invasiva visam intervir nos determinantes da doença e adiar ao máximo a intervenção restauradora com finalidade de preservar o máximo de estrutura dental sadia. O presente relato de caso ilustra e discute o manejo de lesões de cárie e a indicação do tratamento restaurador no contexto intervencionista dos dentistas e demonstra como abordagens conservadoras podem ser realizadas promovendo e mantendo a saúde dos pacientes. 


\section{Referências}

1 - Dutra ER, Chisini LA, Cademartori MG, Oliveira LJC, Demarco FF, Correa MB. Accuracy of partial protocol to assess prevalence and factors associated with dental caries in schoolchildren between 8-12 years of age. Cad Saude Publica. 2018;34(4):e00077217.

2- Sukumaran N, Sharma V, Bhat PK. Dental caries, body mass index, and socioeconomic status among preschoolers in private preschools and anganwadi centers in bengaluru city: a comparative study. Int J Clin Pediatr Dent. 2020;13(6):630-4.

3 - Hadler-Olsen E, Jonsson B. Oral health and use of dental services in different stages of adulthood in Norway: a cross sectional study. BMC Oral Health. 2021;21(1):257.

4 - Chisini LA, Sarmento HR, Horta BL, Demarco FF, Correa MB. Normative and subjective need for dental prosthesis: accuracy and agreement in a population based-study. Cad Saude Publica. 2021;37(2):e0052720.

5 - Chisini LA, Sarmento HR, Collares K, Horta BL, Demarco FF, Correa MB. Determinants of dental prosthetic treatment need: A birth cohort study. Community Dent Oral Epidemiol. 2020.

6 - Chisini LA, Cademartori MG, Conde MCM, Tovo-Rodrigues L, Correa MB. Genes in the pathway of tooth mineral tissues and dental caries risk: a systematic review and meta-analysis. Clin Oral Investig. 2020;24(11):3723-38.

7 - Chisini LA, Cademartori MG, Conde MCM, Costa FDS, TovoRodrigues L, Carvalho RV, et al. Genes and SNPs in the pathway of immune response and caries risk: a systematic review and metaanalysis. Biofouling. 2020;36(9):1100-16.

8 - Chisini LA, Cademartori MG, Conde MCM, Costa FDS, Salvi LC, Tovo-Rodrigues L, et al. Single nucleotide polymorphisms of taste genes and caries: a systematic review and meta-analysis. Acta Odontol Scand. 2021;79(2):147-55.

9 - Nobrega DF, Fernandez CE, Del Bel Cury AA, Tenuta LM, Cury JA. Frequency of Fluoride Dentifrice Use and Caries Lesions Inhibition and Repair. Caries Res. 2016;50(2):133-40.

10 - Cury JA, Oliveira BH, Santos AP, Tenuta LM. Are fluoride releasing dental materials clinically effective on caries control? Dent Mater. 2016;32(3):323-33.

11 - Velo MM, Tabchoury CP, Romao DA, Cury JA. Evaluation of low fluoride toothpaste using primary enamel and a validated $\mathrm{pH}$-cycling model. Int J Paediatr Dent. 2016;26(6):439-47.

12 - Kidd EA, Fejerskov O. What constitutes dental caries? Histopathology of carious enamel and dentin related to the action of cariogenic biofilms. J Dent Res. 2004; 83: CC35-8. 
13 - Gonzalez-Cabezas C. The chemistry of caries: remineralization and demineralization events with direct clinical relevance. Dent Clin North Am. 2010;54(3):469-78.

14 - Marcenes W, Kassebaum NJ, Bernabe E, Flaxman A, Naghavi M, Lopez A, et al. Global burden of oral conditions in 1990-2010: a systematic analysis. J Dent Res. 2013;92(7):592-7.

15 - Cury JA, Ricomini-Filho AP, Berti FLP, Tabchoury CP. Systemic Effects (Risks) of Water Fluoridation. Braz Dent J. 2019;30(5):421-8.

16 - Chisini LA, San Martin AS, Silva JVJBF, Brambatti N, Pietro FS, M. CMC, et al. Brazilian National Health System dental x-ray coverage in Southern Brazil in 2016: an ecological study. Epidemiol Serv Saude. 2019;28(1):e2018090.

17 - Schwendicke F, Tzschoppe M, Paris S. Radiographic caries detection: A systematic review and meta-analysis. J Dent. 2015;43(8):924-33.

18 - Chisini LA, Conde MC, Correa MB, Dantas RV, Silva AF, Pappen FG, et al. Vital Pulp Therapies in Clinical Practice: Findings from a Survey with Dentist in Southern Brazil. Braz Dent J. 2015;26(6):566-71.

19 - Gomez J, Ellwood RP, Martignon S, Pretty IA. Dentists' perspectives on caries-related treatment decisions. Community Dent Health. 2014;31(2):91-8.

20 - Kakudate N, Sumida F, Matsumoto Y, Yokoyama Y, Gilbert GH, Gordan VV. Patient age and dentists' decisions about occlusal caries treatment thresholds. Oper Dent. 2014;39(5):473-80.

21 - Domejean S, Leger S, Maltrait M, Espelid I, Tveit AB, Tubert-Jeannin S. Changes in Occlusal Caries Lesion Management in France from 2002 to 2012: A Persistent Gap between Evidence and Clinical Practice. Caries Res. 2015;49(4):408-16.

22 - Innes NPT, Schwendicke F. Restorative Thresholds for Carious Lesions: Systematic Review and Meta-analysis. J Dent Res. 2017;96(5):501-8.

23 - Paris S, Banerjee A, Bottenberg P, Breschi L, Campus G, Domejean S, et al. How to Intervene in the Caries Process in Older Adults: A Joint ORCA and EFCD Expert Delphi Consensus Statement. Caries Res. 2020;54(5-6):1-7.

24 - Banerjee A, Splieth C, Breschi L, Fontana M, Paris S, Burrow M, et al. When to intervene in the caries process? A Delphi consensus statement. Br Dent J. 2020;229(7):474-82.

25 - Ricketts DN, Pitts NB. Novel operative treatment options. Monogr Oral Sci. 2009; 21:174-87.

26 - Longbottom C, Ekstrand K, Zero D. Traditional preventive treatment options. Monogr Oral Sci. 2009;21:149-55.

27 - Vogel GL. Oral fluoride reservoirs and the prevention of dental caries. Monogr Oral Sci. 2011;22:146-57. 
28 - ICCMS. International Caries Classification and Management System Guide for Practitioners and Educators. 2014.

29 - Marinho VC, Higgins JP, Sheiham A, Logan S. Combinations of topical fluoride (toothpastes, mouthrinses, gels, varnishes) versus single topical fluoride for preventing dental caries in children and adolescents. Cochrane Database Syst Rev. 2004(1):CD002781.

30 - Cury JA, Tenuta LM. Enamel remineralization: controlling the caries disease or treating early caries lesions? Braz Oral Res. 2009;23(Suppl): 123-30.

31 - Pitts NB. Implementation. Improving caries detection, assessment, diagnosis and monitoring. Monogr Oral Sci. 2009;21:199-208.

32 - Topping GV, Pitts NB, International Caries D, Assessment System C. Clinical visual caries detection. Monogr Oral Sci. 2009;21:15-41.

33 - Theocharopoulou A, Lagerweij MD, van Strijp AJ. Use of the ICDAS system and two fluorescence-based intraoral devices for examination of occlusal surfaces. Eur J Paediatr Dent. 2015;16(1):51-5.

34 - Ekstrand KR, Zero DT, Martignon S, Pitts NB. Lesion activity assessment. Monogr Oral Sci. 2009;21:63-90.

35 - Schwendicke F, Jager AM, Paris S, Hsu LY, Tu YK. Treating pit-andfissure caries: a systematic review and network meta-analysis. J Dent Res. 2015;94(4):522-33.

36 - Twetman S, Fontana M. Patient caries risk assessment. Monogr Oral Sci. 2009;21:91-101.

37 - Simonsen RJ. Retention and effectiveness of dental sealant after 15 years. J Am Dent Assoc. 1991;122(10):34-42.

38 - Muller-Bolla M, Lupi-Pegurier L, Tardieu C, Velly AM, Antomarchi C. Retention of resin-based pit and fissure sealants: A systematic review. Community Dent Oral Epidemiol. 2006;34(5):321-36.

39 - Dias KR, Andrade CB, Wait TT, Chamon R, Ammari MM, Soviero VM, et al. Efficacy of sealing occlusal caries with a flowable composite in primary molars: A 2-year randomized controlled clinical trial. J Dent. 2018;74:49-55.

40 - Horuztepe SA, Ergin E, Onen A, Gurgan S. Comparison of Resin Infiltration Technique with Conventional Preventive Applications on Occlusal Fissures in Terms of Chemical Analysis and SEM. Acta Stomatol Croat. 2020;54(4):382-91.

41 - Schwendicke F, Frencken JE, Bjorndal L, Maltz M, Manton DJ, Ricketts D, et al. Managing Carious Lesions: Consensus Recommendations on Carious Tissue Removal. Adv Dent Res. 2016;28(2):58-67.

42 - Schwendicke F, Splieth C, Breschi L, Banerjee A, Fontana M, Paris $\mathrm{S}$, et al. When to intervene in the caries process? An expert Delphi consensus statement. Clin Oral Investig. 2019; 23. 
43 - Pitts NB, Rimmer PA. An in vivo comparison of radiographic and directly assessed clinical caries status of posterior approximal surfaces in primary and permanent teeth. Caries Res. 1992;26(2):146-52.

44 - Hintze H, Wenzel A, Danielsen B, Nyvad B. Reliability of visual examination, fibre-optic transillumination, and bite-wing radiography, and reproducibility of direct visual examination following tooth separation for the identification of cavitated carious lesions in contacting approximal surfaces. Caries Res. 1998;32(3):204-9.

45 - Assaf AV, Meneghim MC, Zanin L, Pardi V, Pereira AC, Ambrosano GM. Influence of diagnostic adjuncts to the measurement of caries prevalence at different caries thresholds. Int Dent J. 2003;53(6):485-90.

46 - Silva RP, Assaf AV, Mialhe FL, Mendes KLC, Meneghim MC, Pereira AC. Dental caries diagnostic thresholds: Which one? Why? When? Int J Public Health. 2020;65(3):371-4.

47 - Ghoneim A, Yu B, Lawrence HP, Glogauer M, Shankardass K, Quinonez C. Does competition affect the clinical decision-making of dentists? A geospatial analysis. Community Dent Oral Epidemiol. 2020;48(2):152-62.

48 - San Martin AS, Chisini LA, Martelli S, Sartori LRM, Ramos EC, Demarco FF. Distribution of Dental Schools and dentists in Brazil: an overview of the labor market. Rev ABENO. 2018;18(1):63-73.

49 - Elderton RJ. Restorations without conventional cavity preparations. Int Dent J. 1988;38(2):112-8.

50 - Demarco FF, Correa MB, Cenci MS, Moraes RR, Opdam NJ. Longevity of posterior composite restorations: not only a matter of materials. Dent Mater. 2012;28(1):87-101.

51 - Chisini LA, Collares K, Cademartori MG, Oliveira LJC, Conde MCM, Demarco FF, et al. Restorations in primary teeth: a systematic review on survival and reasons for failures. Int J Paediatr Dent. 2018;28(2):123-39. 


\title{
Restorative overtreatment: case report and discussion of the restorative treatment decision
}

\begin{abstract}
The present study aimed to report a clinical case of restorative overtreatment and to discuss aspects related to the diagnosis and clinical conduct in the face of carious lesions. The female patient (22 years old) sought dental care at the Faculty of Dentistry of the Federal University of Pelotas. During the reception, the patient reported having been diagnosed with several caries lesions and the need for restorative treatment. Supragingival periodontal examinations showed a Visible Plaque Index of 8.3\% and a Gingival Bleeding Index of $13.54 \%$. No drilling depth greater than $3 \mathrm{~mm}$ was observed. The ICDAS Examination (International Caries Detection and Assessment System) revealed several inactive cavities and cavities, ICDAS scores 2 and 3. Composite resin restorations (class I) were observed on the occlusal surfaces of elements 16, 26 and 46. Thus, the patient was diagnosed without caries disease and with mild biofilm-induced gingivitis. Oral hygiene guidelines were discussed for the treatment of gingivitis and the monitoring of caries lesions was indicated for the case. After 1 year of follow-up, the inactive lesions did not change, demonstrating that conservative approaches are a great option, in addition to avoiding restorative overtreatment. The present study uses the present experience report as a background to discuss the management of dental caries and the indication of restorative treatment based on scientific evidence.
\end{abstract}

KEYWORDS: Dental caries; Decision Making; Case Reports.

\section{Como citar este artigo}

Chisini LA, Gonçalves MSA, Salvi LC, Costa FS, Conde MCM. Sobretratamento restaurador: relato de caso e discussão sobre a decisão do tratamento restaurador. Rev Odontol Bras Central 2021; 30(89): 323-338. DOI: 10.36065/robrac.v30i89.1536 